\title{
TRATAMENTO DE TUMOR ODONTOGÊNICO CERATOCÍSTICO RECIDIVANTE: RELATO DE CASO
}

Sara Barancelli TODERO, Aline Monise SEBASTIANI, Rafaela SCARIOT, Leandro KLUPPEL, Nelson REBELLATO

O tumor odontogênico ceratocístico é um neoplasma cístico benigno, originado a partir de remanescentes da lâmina dental. É uma lesão que possui um comportamento proliferativo, com grande potencial de destruição local e tendência para a multiplicidade. O diagnóstico deve ser realizado baseado nos aspectos clínicos, radiográficos e histopatológicos a fim de se estabelecer 0 diagnóstico final. Esse trabalho relata o caso da paciente T.N.R, gênero feminino, 44 anos, com história de lesão radiolúcida unilocular, com expansão e rompimento de cortical óssea em corpo mandibular entre as raízes dos dentes 47 e 48 . Foi realizado tratamento prévio para remoção da lesão em outro Serviço com insucesso. Sendo assim, optou-se pelo tratamento em dois estágios: I) biópsia incisional com a instalação de um dreno para descompressão da lesão e II) enucleação da lesão e exodontia dos elementos 47 e 48 com aplicação de solução de Carnoy no sítio cirúrgico na tentativa de evitar nova recidiva. A paciente encontra-se em acompanhamento sem queixas funcionais e/ou estéticas. Os exames de imagem de controle da paciente mostraram neoformação óssea na região.

Palavras-chave: Descompressão cirúrgica; Recidiva local de neoplasia; Anormalidades da boca; Neoplasias Maxilomandibulares. 